\title{
Cramer-Rao lower bounds for precision in T2* assessment for myocardial iron overload measurements by T2* multi-echo CMR Vincenzo Positano*1, Antonella Meloni ${ }^{1}$, Alessia Pepe ${ }^{1}$, Maria Filomena Santarelli ${ }^{1}$, Daniele De Marchi ${ }^{1}$, Luca Menichetti ${ }^{1}$, Chiara Dell'Amico1 ${ }^{1}$, Brunella Favilli ${ }^{1}$, Matteo Milanesi ${ }^{1}$, Gianluca Valeri², Luigi Natale ${ }^{3}$, Cristina Tassi ${ }^{4}$, Tommaso Casini ${ }^{5}$, Luigi Landini ${ }^{1}$ and Massimo Lombardi ${ }^{1}$
}

Address: ${ }^{1 " G}$ Monasterio" Foundation and Institute of Clinical Physiology, CNR, Pisa, Italy, ${ }^{2}$ Ospedali Riuniti di Ancona, Ancona, Italy, ${ }^{3}$ Policlinico "Gemelli", Roma, Italy, ${ }^{4}$ Policlinico S. Orsola "L. e A. Seragnoli", Bologna, Italy and ${ }^{5}$ Ospedale Meyer, Firenze, Italy

* Corresponding author

from 13th Annual SCMR Scientific Sessions

Phoenix, AZ, USA. $21-24$ January 2010

Published: 21 January 2010

Journal of Cardiovascular Magnetic Resonance 2010, I 2(Suppl I):P275 doi:10.1 I86/I532-429X-12-SI-P275

This abstract is available from: http://jcmr-online.com/content/I2/SI/P275

(C) 2010 Positano et al; licensee BioMed Central Ltd.

\section{Introduction}

T2* multiecho CMR is an established methodology for assessment of iron overload in heart and other organs. It is commonly recognized that MR sequences used in the clinical practice provide the best precision in $\mathrm{T}^{*}$ measurement in the range $3-20 \mathrm{~ms}$, while an increasing error is expected out of this range. However, the dependence of the expected error from T2* and acquisition parameters is unknown.

\section{Purpose}

The objective of this study is to quantify the precision limit of $2^{*}$ assessment exploiting the Cramer-Rao lower bounds theory (CRLB).

\section{Methods}

CRLB provide a fundamental limit to the accuracy in determination of the $\mathrm{T}^{*}$ value from experimental data; for any estimation method, the error in the parameter (measured as the standard deviation or SD) must be greater that or equal to the CRLB. CRLB for T2* estimation were evaluated tacking into account the statistics (i.e. MR signal and noise) of MR images involved in the measurements obtained from image data acquired during the MIOT project. CRLB were evaluated for several echo times configuration used in the clinical setting on GE $1.5 \mathrm{~T}$ scanners for iron overload evaluation in thalassemia patients.

\section{Results}

Figure 1.a shows CRLB for percent error in commonly used single breath-hold sequences with first echo time at $2 \mathrm{~ms}$ and $1.4 \mathrm{~ms}$, echo spacing $2.26 \mathrm{~ms}, 10$ echoes. Achievable measurement error is lower than $10 \%$ in the range 3-40 ms if minimum TE of $2 \mathrm{~ms}$ is used and lower than $10 \%$ in the range $2.5-40 \mathrm{~ms}$ for minimum TE of 1.4 ms. Only 3 patients $(0.3 \%)$ had a global $\mathrm{T} 2 *<3 \mathrm{~ms}$ among the 1324 patients in the MIOT database. Figure 1.b shows CRLB for percent error for low $\mathrm{T} 2 *$ values for the two single-breath-hold sequences previous described and a multi-breath-hold sequence with minimum echo time of $0.9 \mathrm{~ms}$ and echo interval $0.8 \mathrm{~ms}$. Achievable precision is greatly improved for $\mathrm{T}^{*}<4 \mathrm{~ms}$.

\section{Conclusion}

GRE Multiecho sequences with minimum TE less than 2 ms assure good precision in $\mathrm{T} 2{ }^{*}$ assessment in heart for T2* values less than $3 \mathrm{~ms}$. This limit includes almost all thalassemia patient in a large population studied in Italy during the MIOT project. For patients with very high myocardial iron overload or for measurements in other organs 


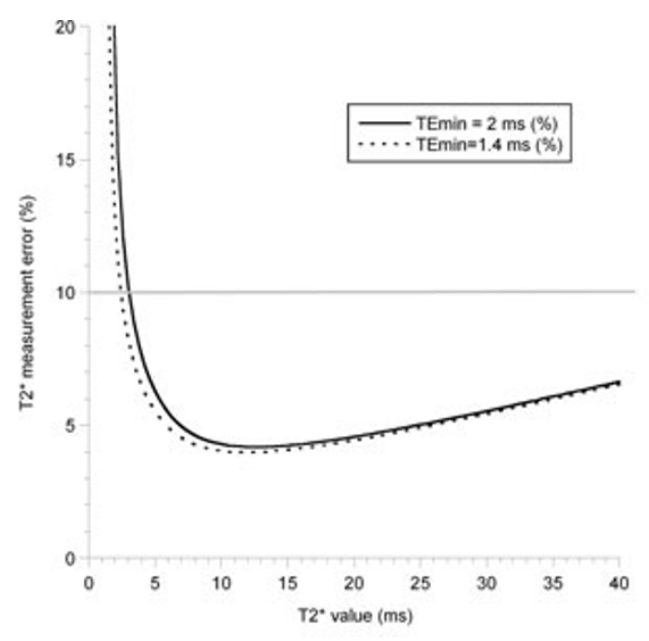

a

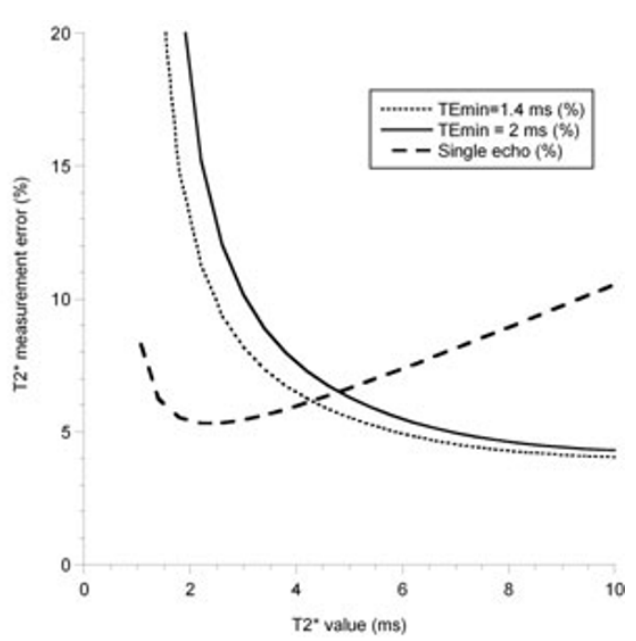

b

\section{Figure I}

\section{CRLB for T2* assessment.}

with heavier iron overload (i.e. liver) sequences with lower minimum echo time and/or lower echoes interval may be useful.
Publish with Biomed Central and every scientist can read your work free of charge

"BioMed Central will be the most significant development for disseminating the results of biomedical research in our lifetime."

Sir Paul Nurse, Cancer Research UK

Your research papers will be:

- available free of charge to the entire biomedical community

- peer reviewed and published immediately upon acceptance

- cited in PubMed and archived on PubMed Central

- yours - you keep the copyright 